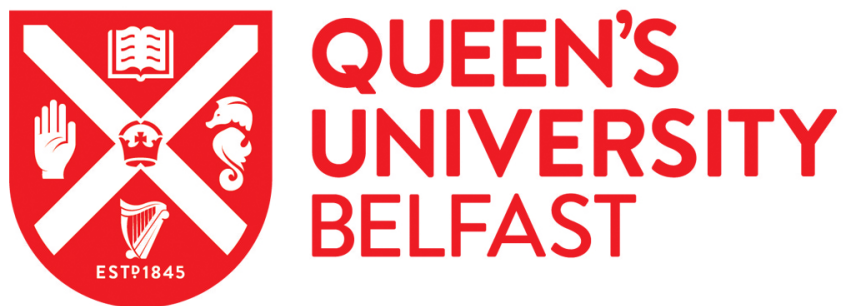

\section{Nanoparticles from Gantrez® AN-poly(ethylene glycol) conjugates as carriers for oral delivery of docetaxel}

Ruiz-Gatón, L., Espuelas, S., Huarte, J., Larrañeta, E., Martin-Arbella, N., \& Irache, J. M. (2019). Nanoparticles from Gantrez® AN-poly(ethylene glycol) conjugates as carriers for oral delivery of docetaxel. International Journal of Pharmaceutics, 118699. https://doi.org/10.1016/j.ijpharm.2019.118699

\section{Published in:}

International Journal of Pharmaceutics

\section{Document Version:}

Peer reviewed version

\section{Queen's University Belfast - Research Portal:}

Link to publication record in Queen's University Belfast Research Portal

\section{Publisher rights}

Copyright 2019 Elsevier B. V.

This manuscript is distributed under a Creative Commons Attribution-NonCommercial-NoDerivs License

(https://creativecommons.org/licenses/by-nc-nd/4.0/), which permits distribution and reproduction for non-commercial purposes, provided the author and source are cited

\section{General rights}

Copyright for the publications made accessible via the Queen's University Belfast Research Portal is retained by the author(s) and / or other copyright owners and it is a condition of accessing these publications that users recognise and abide by the legal requirements associated with these rights.

Take down policy

The Research Portal is Queen's institutional repository that provides access to Queen's research output. Every effort has been made to ensure that content in the Research Portal does not infringe any person's rights, or applicable UK laws. If you discover content in the Research Portal that you believe breaches copyright or violates any law, please contact openaccess@qub.ac.uk. 
Nanoparticles from Gantrez ${ }^{\circledR}$ AN-poly(ethylene glycol) conjugates as carriers for oral delivery of docetaxel

Luisa Ruiz-Gatón, Socorro Espuelas, Judit Huarte, Eneko Larrañeta, Nekane MartinArbella, Juan M. Irache*

Department of Chemistry and Pharmaceutical Technology, NANO-VAC Research Group, University of Navarra, Spain.

*Corresponding author:

Prof. Juan M. Irache

Dep. Chemistry and Pharmaceutical Technology

15

NANO-VAC Research Group

University of Navarra

C/ Irunlarrea, 1

31008 - Pamplona

Spain

20

Phone: +34948425600

Fax: +34948425619

E-mail: jmirache@unav.es 


\section{Abstract}

The oral delivery of docetaxel (DTX) is challenging due to a low bioavailability, related to an important pre-systemic metabolism. With the aim of improving the bioavailability of this cytotoxic agent, nanoparticles from conjugates based on the copolymer of methyl vinyl ether and maleic anhydride (poly(anhydride)) and two different types of PEG, PEG2000 (PEG2) or methoxyPEG2000 (mPEG2), were evaluated. Nanoparticles, with a DTX loading close to $10 \%$, were prepared by desolvation and stabilized with calcium, before purification and lyophilization. For the pharmacokinetic study, nanoparticles were orally administered to mice at a single dose of $30 \mathrm{mg} / \mathrm{kg}$. The plasma levels of DTX were high, prolonged in time and, importantly, quantified within the therapeutic window. The relative oral bioavailability was calculated to be up to $56 \%$ when DTX was loaded in nanoparticles from poly(anhydride)-mPEG2000 conjugate (DTX-NP-mPEG2). Finally, a comparative toxicity study between equitoxic doses of free iv DTX and oral DTX-NP-mPEG2 was conducted in mice. Animals orally treated with DTX-loaded nanoparticles displayed less severe signs of hypersensitivity reactions, peripheral neurotoxicity, myelosuppression and hepatotoxicity than free iv docetaxel. In summary, poly(anhydride)-PEG conjugate nanoparticles appears to be adequate carries for the oral delivery of docetaxel.

Key words: bioavailability; conjugates; docetaxel; nanoparticles; oral delivery; poly(ethylene glycol). 


\section{Introduction}

Docetaxel (DTX), is an antineoplasic agent belonging to the second generation of the taxoid family. This semisynthetic analogue of paclitaxel displays a broad spectrum of antitumor activity and it is considered one of the most potent anticancer drugs in the clinical setting (Verweij et al., 1994; Zhang et al., 2019). It was first described in the 1980s but it was not until the mid 1990s that it was approved by the FDA and consequently used in clinical practice. Docetaxel is a cytotoxic agent that promotes tubulin assembly, stabilizes microtubules and inhibits their depolymerisation, thereby causing mitotic arrest in the $\mathrm{G}_{2} / \mathrm{M}$ phase of the cell cycle and, subsequently, inducing apoptosis (Ogura et al., 2016). Clinically it is widely employed for the treatment of breast, prostate, head and neck, gastric, and non-small cell lung cancers (de Weger et al., 2014).

However, the clinical application of docetaxel is limited by the poor aqueous solubility $(4.93 \mu \mathrm{g} / \mathrm{ml})$, high toxicity and low bioavailability (Dou et al., 2015). The available commercial formulation, Taxotere ${ }^{\circledR}$ or its generic forms, includes a high concentration of Tween ${ }^{\circledR} 80$ and ethanol (50:50 v/v) as excipients for its intravenous administration (Haiqun et al., 2014). Serious dose-limiting toxicities and unpredictable adverse reactions due to either the drug itself or the solvent system have been reported in patients, such as hypersensitivity reactions (Pellegrino et al., 2017), myelosuppression (specially neutropenia) (Hennenfert and Govindan, 2006) and neurotoxicity (Fredriks et al., 2015), requiring the oral administration of corticosteroids and antihistamines before infusion (Mazzaferro et al., 2012). On the other hand, the oral administration of docetaxel is hampered by both its high lipophilicity and low mucosal permeability. In fact, docetaxel is considered as a class IV compound within the Biopharmaceutical classification system (BCS). The permeability of this anticancer drug is hampered by its high affinity for the multidrug efflux transporter P-glycoprotein (P-gp) and the cythocrome P450 enzymatic complex. Both, transporter and metabolic enzymes, are highly expressed in the gastrointestinal (GI) tract limiting the permeation of the drug through the intestinal membrane (van Herwaarden et al., 2007; van Waterschoot et al., 2009).

In order to overcome these drawbacks and improve the oral absorption (bioavailability) of docetaxel, a number of different strategies have been proposed. Among others, the following attempts can be highlighted: coadministration with P-gp selective inhibitors (Malingré et al., 2001; Patel et al., 2015), synthesis of docetaxel analogues (i.e. cabazitaxel, larotaxel) (Vrignaud et al., 2013; Muggia and Kudlowitz, 2014) and the use of formulation approaches such as the combination with cyclodextrins (Wun et al., 2013) or the incorporation in solid dispersions (Song et al., 2016), microemulsions (Yin et al., 2009), nanoemulsions (Pandey et al, 2017), self-nanoemulsifying drug delivery systems (SNEDDS) (Seo et al., 2013), micelles (Hekmat et al., 2016), and nanoparticles (Cho et al., 2014; Feng et al., 2019).

In this context one interesting approach may be the use of nanoparticles from conjugates based on the copolymer of methyl vinyl ether and maleic anhydride (Gantrez ${ }^{\circledast}$ AN). These nanoparticles have been proposed in the recent past as carriers for the mucosal delivery of drugs (Arbós et al., 2003; Yoncheva et al., 2005a). This copolymer is extremely reactive, offering the possibility to react with a large variety of nucleophile and functional groups such as alcohols and amines. In this work, we have 
selected the combination between Gantrez $^{\circledR}$ AN and poly(ethylene glycol) to produce pegylated nanoparticles. In fact, the coating of these poly(anhydride) nanoparticles with PEGs would result in mucus-permeating carriers capable of reaching the surface of the mucosal epithelium in which they would release the loaded drug (Zabaleta et al., 2013; Inchaurraga et al., 2015). In addition, PEGs have been identified as inhibitors of the intestinal P-gp efflux pump (Hugger et al., 2002). Last but not least, the oral toxicity of poly(anhydride) nanoparticles combined with PEGs has been evaluated in vivo confirming its oral safety (Yoncheva et al., 2005b). Particularly, the investigations demonstrated that $\mathrm{LD}_{50}$ was higher than $2000 \mathrm{mg} / \mathrm{kg}$ body weight.

Therefore, in this study, the potential use of nanoparticles prepared from Gantrez ${ }^{\circledR} \mathrm{AN}$ PEG conjugates as carriers for the oral delivery of docetaxel was investigated. In a first

120 step, the Gantrez ${ }^{\circledR}$ AN-poly(ethylene glycol) conjugates were synthesised and characterized. In a second step, these conjugates were used to prepare DTX-loaded nanoparticles. Finally, the pharmacokinetic profiles and the toxicity of DTX-loaded nanoparticles were evaluated in Balb/c mice.

\section{Material and methods}

\subsection{Materials}

Poly(methyl vinyl ether-co-maleic anhydride) or poly(anhydride) (PMV/MA) [Gantrez ${ }^{\circledR}$ AN 119; MW 200,000] was purchased from International Specialty Products ISP/Ahsland 130 Inc (KY, USA). Docetaxel (USP 30, grade 99.0\%) and paclitaxel (USP 28, grade >99.5\%) were supplied by 21CECpharm (London, UK). Taxotere ${ }^{\circledR}$, from Sanofi-Aventis, was provided by the Pharmacy Service of University Clinic of Navarra (Pamplona, Spain). Phosphate buffered saline (PBS), pancreatin, methoxy poly(ethylene glycol) 2000 (mPEG2000) and solid iodine ( $\geq 99.8 \%$ ) were obtained from Sigma Aldrich (MO, USA).

135 Poly(ethylene glycol) with MW of 2000 Da (PEG2000) was provided by Fluka (Buchs, Switzerland). Acetone, ethanol, t-buthylmethylether, acetonitrile and tetrahydrofuran (THF) were obtained from Merck (Darmstadt, Germany). Polysorbate 80 (Tween ${ }^{\circledR} 80$ ) was supplied by Panreac (Barcelona, Spain). Deionised reagent water (18.2 M $\Omega$ resistivity) was prepared by a water purification system (Wasserlab, Pamplona, Spain).

140 The anaesthetic isoflurane (Isoflo ${ }^{\circledR}$ ) was from laboratories Esteve (Barcelona, Spain). All other reagents and chemicals used were of analytical grade and supplied from Sigma Aldrich (MO, USA) and Merck (Darmstadt, Germany).

\subsection{Preparation of Gantrez ${ }^{\circledR}$ AN-poly(ethylene glycol) conjugates (PEG2 and mPEG2)}

Two sets of Gantrez ${ }^{\circledR}$ AN based-conjugates with either poly(ethylene glycol) 2000 or methoxy poly(ethylene glycol) 2000 were synthetized.

For the preparation of Gantrez-PEG2000 conjugate (PEG2), 500 mg Gantrez ${ }^{\circledR}$ AN were firstly dissolved in $100 \mathrm{~mL}$ acetone and heated at 50ㄷ. Then, $25 \mathrm{mg}$ PEG2000 was dissolved in $25 \mathrm{~mL}$ acetone and added to the polymer solution by dripping. The mixture, heated at $50 \circ \mathrm{C}$, was stirred under magnetic stirring for $3 \mathrm{~h}$. Then, the solvent was eliminated by reduced pressure evaporation and the residue was dried (Büchi Rotavapor ${ }^{\circledR}$ R-144; Büchi, Postfach, Switzerland). After collecting the solid, the powder was dispersed in $25 \mathrm{~mL}$ dicloromethane in order to eliminate the remaining free 
PEG2000. The mixtures were sonicated for $1 \mathrm{~min}$ and the supernatant was harvested under vacuum (all-glass filter, Merck Millipore, Darmstadt, Germany). The supernatants were analyzed by TLC (mobile phase dicloromethane-methanol 9:1 v:v) and developed with solid iodine in order to determine the presence of free PEG. The washing process of conjugates with dicloromethane was repeated until the TLC of the supernatant did not show any presence of PEG.

160 The conjugate between mPEG2000 and Gantrez $^{\circledR}$ AN (mPEG2) was prepared and purified in the same way as described before with the only difference that the ratio between mPEG2000 and Gantrez ${ }^{\circledR}$ AN was 0.20 (100 mg mPEG and 500 mg polymer).

\subsection{Physico-chemical characterization of Gantrez $^{\circledR}$ AN-poly(ethylene glycol) conjugates}

After the synthesis, the resulting Gantrez ${ }^{\circledR}$ AN based-conjugates were characterized in order to confirm the binding of the ligand (PEG2000 or mPEG2000) to the polymer backbone as well as to estimate the molecular weight (MW) and the degree of substitution of the resulting compounds.

$170 \quad$ 2.3.1 Infrared spectroscopy (IR)

IR spectroscopy was carried out in a Nicolet Avatar 360FT-IR apparatus (Thermo, WI, USA). This technique allowed us to identify the presence of the carbonyl groups $v(C=O)$ in order to put in evidence the opening of the anhydride ring in the Gantrez ${ }^{\circledR}$ AN backbone through a chemical interaction and the formation of a bond between the 175 carbonyl group of the polymer and a hydroxyl group of the poly(ethylene glycol) (PEG2000 or mPEG2000).

\subsubsection{Nuclear magnetic resonance spectroscopy ( $\left.{ }^{1} \mathrm{H}-\mathrm{NMR}\right)$}

${ }^{1} \mathrm{H}-\mathrm{NMR}$ studies were performed in an Avance 400 apparatus (Bruker, WI, USA) of 400 $\mathrm{MHz}$, using a pulse program zg30 and a waiting time pulses $\left(D_{0}\right)$ of $1 \mathrm{~s}$. The number of 180 accumulations was 64 . Thus, exactly weighted amounts of the Gantrez conjugates (2 $\mathrm{mg}$ ) were dissolved in $500 \mu \mathrm{L}$ deuterated acetone.

The amounts of PEGs associated to the nanoparticles were calculated as described previously (Ojer et al., 2012). For this purpose, the integration of the signal corresponding to the methylated proton in the Gantrez ${ }^{\circledR} \mathrm{AN}(\delta \mathrm{Ha}$ at $4.25 \mathrm{ppm}$ ) was used

185 as reference. For PEG2000 and MPEG2000, the reference signals were bands produced by protons identified with $\delta \mathrm{He}$ at $3.59 \mathrm{ppm}$ and $\delta \mathrm{Hf}$ at $3.62 \mathrm{ppm}$, respectively (see supplementary material). The amount of the PEG (PEG2000 or mPEG2000) bound to the polymer backbone in the synthetised conjugates was then estimated using the following $\delta \mathrm{Ha} / \delta \mathrm{He}$ and $\delta \mathrm{Ha} / \delta \mathrm{Hf}$ ratios.

\subsubsection{HPLC with Evaporative Light Scattering Detector (HPLC-ELSD)}

The amounts of PEG bound to the polymer were also estimated by HPLC (Agilent model 1100 series LC, Agilent, Wokingham, UK) coupled to an Evaporative Light Scattering Detector (ELSD) (Alltech, NY, USA) following the procedure reported by Zabaleta et al. with minor modifications (Zabaleta et al., 2007). Separation was carried out on a PLaquagel-OH column (300 mm x $7.5 \mathrm{~mm}$; particle size $5 \mu \mathrm{m}$ ) (Agilent, Wokingham, UK), in a gradient elution with methanol-water as mobile phase at a flow rate of $1 \mathrm{~mL} / \mathrm{min}$. ELSD conditions were optimized in order to achieve maximum sensitivity: the drift tube temperature was set at $90^{\circ} \mathrm{C}$, the nitrogen flow was maintained at $3.2 \mathrm{~L} / \mathrm{min}$ and the 
gain was set to 2 . Under these experimental conditions, retention times for PEG2000 and $\mathrm{mPEG} 2000$ were $7.1 \pm 0.03$ and $6.9 \pm 0.08 \mathrm{~min}$, respectively.

For calculations, an exactly weighed amount of non-purified conjugate was dissolved in $5 \mathrm{~mL}$ acetone. Then, $5 \mathrm{~mL}$ of ethanol followed by $5 \mathrm{~mL}$ of an aqueous solution containing $2 \%(\mathrm{v} / \mathrm{v}) \mathrm{CaCl}_{2}$ 0.8\% were added and the just formed suspension was centrifuged at 27,000xg for 20 min (Sigma 3 K30, Munich, Germany). The supernatants were collected and quantified by HPLC as described above. The amount of either PEG2000 or mPEG2000 bound to the poly(anhydride) backbone was calculated as the difference between the initial PEG added for the preparation of the conjugates and the amount of PEG recovered from the supernatants. Each sample was assayed in triplicate and the results were expressed as the amount of poly(ethylene glycol) per mg of conjugate.

\subsection{Preparation of DTX-loaded nanoparticles (DTX-NP-PEG2 and DTX-NP-mPEG2)}

Briefly, $100 \mathrm{mg}$ conjugate (PEG2 or mPEG2) were dissolved in $3 \mathrm{~mL}$ acetone. In parallel, $10 \mathrm{mg}$ DTX were dispersed in $2 \mathrm{~mL}$ acetone. Both phases (conjugate and docetaxel) were then mixed under magnetic stirring and the nanoparticles formed by the addition of 5 $215 \mathrm{~mL}$ of ethanol followed by the addition of $5 \mathrm{~mL}$ of an aqueous solution containing $2 \%$ $(\mathrm{v} / \mathrm{v}) \mathrm{CaCl}_{2} 0.8 \%$. The organic solvents were eliminated by evaporation under reduced pressure and the resulting suspensions were filtered through a $0.45 \mu \mathrm{m}$ membrane and purified by centrifugation (Sigma 3 K30, Munich, Germany) at 27,000xg for 20 minutes. The pellets were resuspended in water and the purification step was repeated again.

220 Finally, the formulations were frozen and freeze-dried (Genesis 12EL Freeze Dryer; Virtis, PA, USA) using sucrose ( $5 \% \mathrm{w} / \mathrm{v})$ as cryoprotector.

Empty nanoparticles (NP-PEG2 and NP-mPEG2) were prepared in the same way as described above but in absence of docetaxel and used as controls.

For the identification of the different pegylated nanoparticle formulations, the following 225 abbreviations were used: NP-PEG2 (nanoparticles prepared from the conjugate between Gantrez ${ }^{\circledR} A N$ and PEG2000), NP-mPEG2 (nanoparticles prepared from the conjugate between Gantrez ${ }^{\circledR} \mathrm{AN}$ and mPEG2000), DTX-NP-PEG2 (docetaxel-loaded nanoparticles prepared from the conjugate between Gantrez ${ }^{\circledR} \mathrm{AN}$ and PEG2000) and DTX-NP-mPEG2 (docetaxel-loaded nanoparticles prepared from the conjugate between 230 Gantrez ${ }^{\circledR} \mathrm{AN}$ and $\left.\mathrm{mPEG} 2000\right)$.

\subsection{Characterization of DTX-loaded nanoparticles}

\subsubsection{Physico-chemical characterization}

The size and zeta potential of the systems were determined by photon correlation spectroscopy (PCS) and electrophoretic laser Doppler anemometry, respectively, using a Zetaplus analyser system (Brookhaven Instruments Corporation, NY, USA). The nanoparticles mean diameter was determined after dispersion in ultrapure water and measured at $25^{\circ} \mathrm{C}$ by dinamic light scattering angle of $90^{\circ} \mathrm{C}$, and the surface charge was determined by dilution of $200 \mu \mathrm{L}$ the samples in $2 \mathrm{~mL}$ of a $0.1 \mathrm{mM} \mathrm{KCl}$ solution ( $\mathrm{pH}$ 7.4). The yield of the process was calculated by gravimetry as described previously (Arbós et al., 2003).

The morphology and shape of the nanoparticles were examined and microphotographed by field emission scanning electron microscopy (FESEM) in a Zeiss 
Ultra Plus scanning electron microscope (Carl Zeiss SMT, Oberdochen, Germany) operating between 1 and $2 \mathrm{kV}$ from $3 \mathrm{~mm}$ distance. Prior analysis and in order to enhance the quality of the images, particles were washed to remove the cryoprotector. For this purpose, freeze-dried nanoparticles were resuspended in ultrapure water and centrifuged at $27,000 \mathrm{xg}$ for $10 \mathrm{~min}$. Then, the supernatants were rejected and the obtained pellets were mounted on copper grids. Finally, the pellet was shaded with a gold/palladium (Au/Pd) layer in a Q150R Sputter-Coater (Quorum Technologies, Ashford, UK).

\subsubsection{Docetaxel content in nanoparticles}

The amount of docetaxel loaded into nanoparticles was quantified by HPLC-UV in an Agilent model 1200 series LC coupled to a diode-array detector (Agilent) set at $228 \mathrm{~nm}$. The chromatographic system was equipped with a reversed-phase $150 \mathrm{~mm} \times 3 \mathrm{~mm} \mathrm{C18}$ Phenomenex Gemini column (particle size $5 \mu \mathrm{m}$; Phenomenex, CA, USA) and protected by a $0.5 \mu \mathrm{m}$ precolumn filter. The mobile phase consisted of phosphate buffer $(0.01 \mathrm{M}$; $\mathrm{pH} 2.1)$ and acetonitrile $(50: 50 \mathrm{v} / \mathrm{v})$ eluted at $0.5 \mathrm{~mL} / \mathrm{min}$. The column was placed at $30^{\circ} \mathrm{C}$ and the injection volume was $100 \mu \mathrm{L}$. Paclitaxel (PTX) was used as internal standard. Under these experimental conditions the run time was $16 \mathrm{~min}$ and paclitaxel and docetaxel eluted at 6.8 and $8.2 \mathrm{~min}$, respectively. For the calculations, the standard curve of docetaxel was designed over the range between 1.25 and $320 \mu \mathrm{g} / \mathrm{mL}\left(r^{2}>0.999\right)$. The limit of quantification was calculated as $60 \mathrm{ng} / \mathrm{mL}$ with a relative standard deviation of $4.5 \%$. For analysis, nanoparticles were digested with acetonitrile (1:8 volume ratio)

265 and assayed in triplicate. The results were expressed as the amount of DTX $(\mu \mathrm{g})$ per $\mathrm{mg}$ of nanoparticles. The encapsulation efficiency (E.E) was calculated as follows:

$$
\operatorname{E.E}(\%)=\left(Q_{\text {associated }} / Q_{\text {initial }}\right) \times 100
$$

Where $Q_{\text {initial }}$ is the initial amount of DTX added and $Q_{\text {associated }}$ is the amount of entrapped DTX in the nanoparticles which is calculated by HPLC.

\subsection{In vitro release study}

In vitro drug release experiment was carried out at $37^{\circ} \mathrm{C}$ using simulated gastric (SGF; $\mathrm{pH} 1.2$ ) and intestinal (SIF; pH 6.8) fluids containing $0.5 \%$ of polysorbate 80 ( Tween $^{\circledR} 80$ ) as solubilising agent for docetaxel to maintain sink conditions.

275 Drug-release patterns were evaluated by using dialysis cassettes (Slide-A-Lyzer ${ }^{\circledR}$, Thermo Scientific, MA, USA; MW cut off: 10,000). For this purpose, dialysis cassettes were filled with a suspension of nanoparticles in water (containing $7.5 \mathrm{mg}$ docetaxel) and placed in $300 \mathrm{~mL}$ of SGF at $37^{\circ} \mathrm{C}$ under magnetic stirring for two hours. As control, free docetaxel (dissolved in distilled water containing $25 \%$ Tween 80 and $9.75 \%$ ethanol) was employed. After $2 \mathrm{~h}$ under SGF, the cassettes were collected and placed in $300 \mathrm{~mL}$ SIF at the same temperature. At predetermined time intervals, $1 \mathrm{~mL}$ samples were withdrawn from the receptor compartment and replaced immediately with the same volume of fresh simulated fluid to maintain a constant release volume. Finally, samples were filtered and the amount of docetaxel released from the formulations was quantified by HPLC analysis as previously described (calibration curves of free docetaxel in supernatants obtained from SGF and SIF, $\left.r^{2}>0.999\right)$. Release profiles were expressed in terms of cumulative release percentage, and plotted versus time. 


\subsection{Pharmacokinetic studies}

290 Pharmacokinetic studies were performed on Balb/c female mice (average weight 19-22 g) obtained from Harlan (Santiga, Spain). Animal experiments were carefully reviewed and approved by the Ethical Committee for Animal Experimentation at the University of Navarra (Spain) (protocol number 169-12). Before the experiment, animals were adaptively fed for 1 week with free access to food and drinking water ( $12 \mathrm{~h}$ day/night

295 cycle, temperature $22 \pm 2^{\circ} \mathrm{C}$, relative humidity $\left.55 \pm 10 \%\right)$. The mice were fasted overnight prior to the study.

The animals were randomly divided into treatment groups $(n=16)$. Each time point corresponded to 4 animals. The experimental groups were as follows: (a) DTX-NP-PEG2 and (b) DTX-NP-mPEG2. Nanoparticles were dispersed in purified water and each animal 300 received orally a volume (about $200 \mu \mathrm{L}$ ) of nanoparticle suspension, corresponding to a docetaxel dose of $30 \mathrm{mg}$ drug per $\mathrm{kg}$ body weight (bw), with a blunt needle via the esophagus into the stomach. As controls, one group of animals received Taxotere ${ }^{\circledR}$ (DTX) intravenously via the tail vein as a slow infusion and another group was treated with the commercial formulation orally. In both cases, the anticancer drug was diluted with either purified water (oral) or sterile saline (intravenous) and the dose was again 30 $\mathrm{mg} / \mathrm{kg}$ body weight. All the animals were observed for their general condition and clinical signs.

Blood samples were obtained from four animals per time point at $0,0.08,0.25,0.5,1$, $2,4,6,8$ and $12 \mathrm{~h}$ following iv administration and $0,0.5,1,1.5,3,4,6,8,12,24,48$ and

$31072 \mathrm{~h}$ following oral administration. EDTA was used as an anticoagulant agent. Blood volume was recovered intraperitoneally with an equal volume of normal saline solution preheated at body temperature. The plasma was separated into clean tubes by centrifugation at 2,500xg for 10 minutes and kept frozen at $-80^{\circ} \mathrm{C}$ until HPLC analysis.

\subsubsection{Determination of DTX plasma concentration by HPLC-UV}

315 The amount of docetaxel was determined in plasma by HPLC-UV as described above. The extraction method was adapted from Zhao et al. (2009). Calibration curves were used for the conversion of the DTX/PTX chromatographic area to the concentration. Calibrator and quality control samples were prepared by adding appropriate volumes of standard docetaxel ethanolic solution to drug free plasma. Calibration curves were 320 designed over the range between 100 and $3200 \mathrm{ng} / \mathrm{mL}\left(r^{2}>0.999\right)$. An aliquot $(200 \mu \mathrm{L})$ of plasma was mixed with $25 \mu \mathrm{L}$ of internal standard solution (paclitaxel, $10 \mu \mathrm{g} / \mathrm{mL}$ in ethanol). After vortex mixing, liquid-liquid extraction was accomplished by adding $3 \mathrm{~mL}$ of tert-buthylmethylether following vortex gentle agitation (10 $\mathrm{min}$ ). The mixture was centrifuged for $10 \mathrm{~min}$ at 2,500xg, and then, the organic layer was transferred to a clean

325 tube and evaporated until dry (Thermo Savant, Barcelona, Spain). Finally, the residue was dissolved in $125 \mu \mathrm{L}$ of reconstitution solution (acetonitrile-phosphate buffer; 0.01 $\mathrm{M} ; \mathrm{pH}=2.1 ; 50: 50 \mathrm{v} / \mathrm{v}$ ) and placed in the HPLC. A hundred microlitre-aliquot of each sample was injected onto the HPLC column. Under these experimental conditions, the UV detection of docetaxel was performed at $228 \mathrm{~nm}$ and the run time was $16 \mathrm{~min}$. The limit of quantification was calculated to be $140 \mathrm{ng} / \mathrm{mL}$ with a relative standard deviation of $5.3 \%$.

\subsubsection{Calculation of pharmacokinetic parameters}


The pharmacokinetic analysis was performed based on a non-compartmental model using WinNonlin 5.2 software (Pharsight Corporation, MO, USA). The following parameters were estimated: maximal plasmatic concentration $\left(C_{\max }\right)$, time in which the maximum concentration is reached $\left(T_{\max }\right)$, area under the concentration-time curve from time 0 to $t h(A \cup C)$, mean residence time (MRT), clearance $(\mathrm{Cl})$, volume of distribution $(\mathrm{V})$ and half-life of the terminal phase $\left(\mathrm{t}_{1 / 2 z}\right)$. Furthermore, the relative oral bioavailability (Fr) of docetaxel was calculated using the ratio of dose-normalized AUC values following oral and iv administrations:

$$
\operatorname{Fr}(\%)=A_{U} C_{\text {oral }} / A U_{\text {iv }} \times 100 \quad \text { (Eq.2) }
$$

Where $A \cup C_{\text {oral }}$ and $A \cup C_{i v}$. correspond to the areas under the plasmatic curve for the oral and intravenous administrations, respectively.

\section{$345 \quad 2.8$ In vivo toxicity studies}

Toxicity studies were performed on Balb/c female mice (average weight 19-22 g) purchased from Harlan (Santiga, Spain). Animal experiments were carried out in compliance with the regulations of the responsible committee of the University of Navarra (Spain) (protocol number 169-12) in line with the European legislation on 350 animal experiments (86/609/EU).

On the day of arrival, animals were housed under standard facilities and given free access to food and drinking water. Housing conditions were maintained by control temperature and humidity and with 12-hour on-off light cycles. Animals were allowed at least 1 week to acclimate to the environment prior to any experiments. The mice were fasted overnight prior to the study.

On the day of the experiments, mice were randomly distributed into the following groups: (i) Control group (non-treated animals) ( $n=5)$; (ii) DTX group ( $n=5)$ weekly treated with $30 \mathrm{mg} / \mathrm{kg}$ Taxotere $^{\circledR}$ (after dilution in sterile saline) by the intravenous route via the tail vein of mice; and (iii) the nanoparticle treatment group $(n=8)$ that received three times per week an oral dose of $20 \mathrm{mg} / \mathrm{kg}$ (as $200 \mu \mathrm{L}$ of a suspension of DTX-NP-mPEG2 in water). To sum up, animals of the DTX group received three doses of $30 \mathrm{mg} / \mathrm{kg}$ (1 dose per week), whereas the animals treated with the nanoparticle formulation received nine doses of $20 \mathrm{mg} / \mathrm{kg}$ (3 doses per week).

Individual animal weights were registered on day 0 and three times per week during 35

365 days. Similarly, at these time intervals defined, mice were also observed for any clinical signs of toxicity including piloerection, passivity, skin reactions, gastrointestinal toxicity and peripheral neuropathy. Mucosal injury, which leads to gastrointestinal toxicity such as vomiting and diarrhea in clinical settings, was examined. Peripheral neuropathy was considered as damage to the peripheral nerves with clinical observations such as impaired gait, hind limb foot splay, or hind limb paralysis. Reactions severity was classified in following categories depending on their severity: i) (-) absent; ii) (+) weak; iii) $(++)$ moderate; and iv) (+++) strong.

At designated times, blood samples were extracted from the retro-orbital sinus under isoflurane anesthesia for haematological and biochemical analysis respectively. Heparinized plasma used for biochemical analysis was obtained by centrifugation at $2500 \mathrm{xg}$ for $10 \mathrm{~min}$. For hematological analysis, the following hematological parameters were analyzed: hemoglobin ( $\mathrm{HGB} ; \mathrm{g} / \mathrm{L})$, hematocrit $(\mathrm{HCT}, \%)$, red blood corpuscles count 
(RBC; $10^{6} / \mu \mathrm{L}$ ), mean corpuscular volume (MCV; fl), mean corpuscular hemoglobin ( $\mathrm{MCH}$; $\mathrm{pg})$, mean corpuscular hemoglobin concentration (MCHC; g/dL) and white blood corpuscles count (WBC; $\left.10^{3} / \mu \mathrm{L}\right)$. The blood analysis was performed on a Sysmex XT1800i hematology analyzer (Roche Diagnostics Ltd., Basel, Switzerland). WBC differential count was performed by microscopic examination using a Nikon Eclipse Ci microscope (Nikon Instruments, Melville, NY, USA). The absolute neutrophil count (ANC; $10^{3} / \mu \mathrm{L}$ ) was obtained using the following formula: percentage of neutrophils in the differential count $x$ total WBC.

For biochemical analyses, the levels of aspartate transaminase (AST; U/L), alanine transaminase $(A L T ; U / L)$, creatinine $(\mathrm{mg} / \mathrm{dL})$ and urea $(\mathrm{mg} / \mathrm{dL})$ were determined with a Hitachi $911^{\mathrm{TM}}$ autoanalyzer (Roche Diagnostics Ltd., Basel, Switzerland) using the protocols obtained from Roche for the determination of standard parameters.

\subsection{Statistical analysis}

Data are expressed as the mean \pm S.D. of at least three experiments. The non parametric Kruskall-Wallis followed by $U$ Mann-Whitney test was used to investigate statistical differences. In all cases, $\mathrm{p}<0.05$ was considered to be statistically significant. All data processing was performed using GraphPad Prism 6.0 statistical software program (GraphPad Software, CA, USA).

\section{Results}

$400 \quad 3.1$ Preparation and characterization of Gantrez ${ }^{\circledR}$ AN-poly(ethylene glycol) conjugates Figure 1 shows the infrared spectra of the poly(anhydride) and its conjugates with either PEG2000 or mPEG2000 (PEG2 or mPEG2 conjugates). In the analysis of the two derivatives, a new band at $\sim 1706 \mathrm{~cm}^{-1}$ appeared in the spectra. This band would be associated with the stretching of the carbonyl group $v(C=O)$, suggesting a nucleophilic substitution reaction between PEG and Gantrez.

Supplementary material compiles the spectra obtained from the analysis of conjugates from ${ }^{1} \mathrm{H}$-RMN. Figure $1 \mathrm{~S}$ shows the spectrum of Gantrez ${ }^{\circledR} \mathrm{AN}$ in which five main chemical shifts appear. The signal "a" corresponding to the hydrogen of the $\mathrm{CH}$ groups was used as reference for quantifications. Figures $2 S$ and $3 S$ display the spectra for PEG2000 and mPEG2000, respectively. For both PEG2000 and mPEG2000 spectra, the characteristics signals for $\mathrm{CH} 2$ groups were observed: 3.59 ppm (signal "e") for PEG2000 and 3.62 ppm (signal " $f$ ") for mPEG2000. All of these shifts ("a" and " $e$ " or " $f$ ") appeared in the spectra of conjugates (Figures $4 \mathrm{~S}$ and $5 \mathrm{~S}$ ).

From these spectra, the substitution degree (DS) and the MW of the new conjugates were calculated. For PEG2, the DS was calculated to be 2.1 whereas for MPEG2, this value was estimated to be 7.1. As a result, and taken into account that the MW of Gantrez AN (as defined by the manufacturer) was $216 \mathrm{kDa}$, the resulting conjugates were calculated to be 220.6 and $230.8 \mathrm{kDa}$, respectively. These results were confirmed by HPLC-ELSD analysis (Table 1 ).

\subsection{Preparation and characterization of DTX-loaded nanoparticles}

Table 2 summarizes the main physico-chemical characteristics of the different 
docetaxel-loaded nanoparticles obtained from the Gantrez ${ }^{\circledR}$ AN-PEG conjugates. Nanoparticles obtained from the Gantrez ${ }^{\circledR}$ AN-PEG2000 conjugate displayed bigger sizes that those prepared from mPEG2. Thus, for DTX-NP-PEG2, the mean size was close to $420 \mathrm{~nm}$ while for DTX-NP-mPEG2 the mean diameter was around $340 \mathrm{~nm}$. In both cases, the polydispersity of nanoparticles was low with a polydispersity index (PDI) under 0.3. Similarly, the yield of the preparative process was quite similar and around $60 \%$. Regarding zeta potential, DTX-NP-PEG2 and DTX-NP-MPEG2 formulations displayed negative surface charges, slightly higher for nanoparticles obtained from mPEG2 than from PEG2 conjugates (about -37 vs. $33 \mathrm{mV}$ ). Empty nanoparticles displayed similar physico-chemical characteristics than the DTX-loaded ones; except for the yield of the process, which was slightly higher than in the presence of the anticancer drug (about $70 \%$ ). Likewise, the mean size of empty nanoparticles was found to be slightly smaller than in the presence of docetaxel (see Table 2).

Finally, the amount of docetaxel encapsulated into the nanoparticles was independent of the conjugate used to prepare these carriers. Thus, in both cases, the drug loading was close to $10 \%$ (100 $\mu \mathrm{g}$ DTX/mg NP), with an encapsulation efficiency of about $60 \%$. Figure 2 shows the morphology of nanoparticles when observed by FESEM. Both types 440 of nanoparticles displayed a spherical shape with a slightly rough and irregular surface. Interestingly, the apparent size measured from FESEM images were found in good agreement with that determined by photon correlation spectroscopy.

\subsection{In vitro release study}

445 The release of docetaxel was evaluated in simulated gastric and intestinal fluids supplemented with Tween 80 (Figure 3). The dialysis membrane did not importantly affect the release of free docetaxel from the reservoir (Float-A-Lyzer device) to the external medium (SGF or SIF). When nanoparticles were dispersed in SGF for two hours, the amount of the loaded drug released in this period of time was always less than $10 \%$.

450 In contrast, when nanoparticles were incubated in the SIF, docetaxel was released more rapidly. For DTX-NP-PEG2, the profile was characterised by a quick initial release during the first 4 hours in which more than the $50 \%$ of the loaded drug was released followed by a more sustained deliverance phase. For DTX-NP-MPEG2, the release profile in SIF appeared to be linear and constant during the first 10 hours in which close to the $80 \%$

455 of the loaded drug was released. A complete release of docetaxel was obtained for all samples at 30 hours after the beginning of the study.

\subsection{Pharmacokinetic studies}

The plasma concentration-time curve after a single intravenous and oral administration of docetaxel at $30 \mathrm{mg} / \mathrm{kg}$ and the oral administration of docetaxel loaded in the different poly(anhydride)-PEG conjugate nanoparticles at $30 \mathrm{mg} / \mathrm{kg}$ are shown in Figure 4 . On the one hand, after the iv administration of commercial docetaxel, the drug plasma concentration presented a nonlinear profile with detectable levels of docetaxel until 12 hours post-administration. On the other hand, when DTX was administered orally, the plasma levels were below the limit of detection of the HPLC technique. By contrast, the oral administration of the poly(anhydride)-PEG conjugate nanoparticles offered high and sustained plasma levels of the anticancer drug. These plasma curves were 
characterized by an initial first phase of about 1.5-2 hours in which the docetaxel plasma levels increased till reaching the $C_{\max }$, followed by a phase of about 70 hours in which the amount of the anticancer drug in plasma was found to decrease in a slow and sustained way. Moreover, it is interesting to note that docetaxel plasma levels were within the therapeutic window (between $35 \mathrm{ng} / \mathrm{mL}$ and $2700 \mathrm{ng} / \mathrm{mL}$, minimum and maximum tolerated dose respectively) in both cases.

Table 3 summarizes the main pharmacokinetic parameters derived from the oral and intravenous plasma curves estimated by a non-compartmental analysis. Firstly, for the commercial formulation administered by means if the iv route, the mean value of AUC was $145 \mu \mathrm{g} \mathrm{h} / \mathrm{ml}$ with a maximum concentration $\left(C_{\max }\right)$ of $178 \mu \mathrm{g} / \mathrm{ml}$. The mean residence time (MRT) and the half-life of the terminal phase $(t 1 / 2 z)$ of the curve were estimated to be $1.5 \mathrm{~h}$. The clearance $(\mathrm{Cl})$ of docetaxel was $0.2 \mathrm{~L} / \mathrm{h} / \mathrm{kg}$ and the volume of 480 distribution (V) of the drug was about $0.5 \mathrm{~L} / \mathrm{kg}$.

As observed in Table 3, the docetaxel $\mathrm{C}_{\max }$ for the nanoparticle formulations were found to be about 100-times lower than for the drug formulation administered by the iv route. The $\mathrm{T}_{\max }$ was delayed to $1.5 \mathrm{~h}$ for oral DTX-NP-mPEG2 formulation and to $2 \mathrm{~h}$ for oral DTX-NP-PEG2 formulation. Similarly, for DTX-NP-PEG2 and DTX-NP-mPEG2, AUC values

485 were 2.5 and 1.8-times lower than the AUC obtained after a single intravenous administration of free docetaxel, respectively. In addition, for DTX-NP-mPEG2, AUC value was 1.4-fold higher than calculated for DTX-NP-PEG2. With these values, the relative oral bioavailability $(\mathrm{Fr})$ of docetaxel was found to be $56 \%$ for DTX-NP-mPEG2 and $40 \%$ for DTX-NP-PEG2.

490 On the other hand, the mean residence time (MRT) of the drug in plasma and its halflife of the terminal phase $\left(t_{1 / 2 z}\right)$ were greatly extended when administered in the nanoparticle formulations by the oral route. Thus, the half-life of docetaxel $\left(t_{1 / 2 z}\right)$ was about 24-29 times higher when the drug was administered orally in the nanoparticles than when given as free drug (DTX) by the intravenous route. In the same way, the volume of distribution (V) of the anticancer drug when loaded in nanoparticles was significantly higher (11.2 and $14.1 \mathrm{~L} / \mathrm{kg}$ for DTX-NP-PEG2 and DTX-NP-mPEG2) than when the drug was intravenously administered. On the contrary, the clearance of docetaxel was always similar and independent of both the formulation and the route of administration used.

\subsection{In vivo toxicity studies}

In order to gain insight about the toxicity induced by docetaxel when administered orally in the form of nanoparticles, DTX-NP-mPEG2 was administered at a dose of $20 \mathrm{mg} / \mathrm{kg}$ three times per week during three consecutive weeks (9 doses). For comparisons, DTX was also administered weekly intravenously at a dose of $30 \mathrm{mg} / \mathrm{kg}$ for three consecutive weeks (3 doses). For the group of mice treated with DTX intravenously, the animals suffered of a significant weight loss during the period in which they received the drug (about 15\% of their original weight) (Figure 5). Nevertheless, after the suppression of the treatment, the animals recovered their normal weight. For animals treated with

510 DTX-NP-mPEG2 orally, their slimming was in all cases less than $5 \%$ of their original weight (Figure 5). Significant differences were observed in the body weight of the 
animals treated with iv DTX compared with the control mice (non-treated animals) $(p<0.05)$ and with DTX-NP-mPEG2 treated group ( $p<0.01$, data not shown).

Table 4 summarizes the most important signs of toxicity recorded throughout the study.

515 For animals treated with either DTX or DTX-NP-MPEG2, one animal of each group died. More particularly, the animals treated iv with free docetaxel displayed a low mobility and signs of bristly hair and respiratory distress (Table 4). These clinical signs were more severe just after each drug administration. For animals treated orally with DTX-NPmPEG2 any sign of disease stress and prejudice of their health status was observed 520 (Table 4).

On the other hand, on day 21 after the first administration, animals treated with DTX showed clinical signs of peripheral neuropathy such as impaired gait and hind limb splay (2/5); however, no neurotoxicity reactions appeared on the control group and the animals treated with oral nanoparticles. On the other hand, on day 35 after the first

525 administration, serious dermatitis/necrosis (skin reactions) were noted on the tails of mice $(2 / 5)$ treated iv with DTX (data not shown).

After the oral administration of docetaxel-loaded in poly(anhydride)-mPEG 2000 conjugate nanoparticles or the iv docetaxel, the hematology parameters were analyzed. Figure 6 summarizes the changes in $\mathrm{RBC}, \mathrm{HCT}, \mathrm{Hb}$ and $\mathrm{MCHC}$ both in the medium (day 53014 ) and the late-term (day 35 ) of the test. As observed, on day 14, mice treated with iv docetaxel showed a marked decrease in RBC (65\%), HCT (50\%), Hb (65\%) and MCHC (30\%), compared with those of the basal levels (day 0). These data were correlated with mean values of $\mathrm{RBC}<8 \times 10^{6} / \mu \mathrm{L}, \mathrm{HTC}<40 \%, \mathrm{Hb}<14 \mathrm{~g} / \mathrm{dL}$ and $\mathrm{MCHC}<35 \mathrm{~g} / \mathrm{dL}$, which were associated with anemia (Wolford et al., 1986). Although, no treatment-related changes

535 were noted after the oral administration of DTX-NP-mPEG2.

Figure 7 represents the changes in WBC and ANC. As can be seen in Figure 7A, on day 21 and 35, the animals treated with iv DTX displayed a marked decrease in the WBC levels compared with nanoparticles group ( $70 \%$ vs. $40 \%$ of the basal levels (day 0 ), respectively) and could be correlated with mean values of $\mathrm{WBC}<3.5 \times 10^{3} / \mu \mathrm{L}$, which

540 evidenced moderate leukopenia at these time points (Wolford et al., 1986; Olfert et al., 1993). Besides, as observed in Figure 7B, docetaxel administered intravenously reduced significantly the ANC with mean values $<1.0 \times 10^{3} / \mu \mathrm{L}$, which implied that the mice of this group developed moderate neutropenia (Wolford et al., 1986). By contrast, the effect on mice after administration of DTX-NP-mPEG2 was less severe.

545 Other hematologic markers including mean corpuscular haemoglobin (MCH) and mean corpuscular volume (MCV) had no statistically significant differences among the two groups (data not shown). Regarding WBC differential count, no obvious differences between both treatments were found.

Finally, to assess the systemic toxicity of formulations, a number of biochemical 550 parameters in serum such as AST, ALT, urea and creatinine, were also measured. Table 5 shows the biochemical parameters registered. The values were always within the reference ranges (Olfert et al., 1993). However, the AST and ALT values on day 7 showed significant differences between DTX and DTX-NP-mPEG2 $(p<0.05)$.

\section{Discussion}


The synthesis of Gantrez ${ }^{\circledR}$ AN-poly(ethylene glycol) conjugates (PEG2 and mPEG2) was performed after dissolving the copolymer of methyl vinyl ether and maleic anhydride and the PEG in acetone, at a temperature of $50^{\circ} \mathrm{C}$ for 3 hours, following by purification step with dichloromethane and a final drying step. The reaction between the carbonyl 560 group of the Gantrez ${ }^{\circledR}$ AN and a hydroxyl group of the poly(ethylene glycol) was confirmed by $I R$ analysis (Figure 1 ) and ${ }^{1} \mathrm{H}-\mathrm{RMN}$ (Supplementary material). The substitution degree was calculated to be 2.1 for PEG2 conjugate (about $21 \mu \mathrm{g}$ of PEG2000 per mg of conjugate) and 7.1 for mPEG2 conjugate (71 $\mu \mathrm{g}$ of PEG2000 per mg of conjugate).

565 Nanoparticles from both Gantrez ${ }^{\circledR}$ AN-PEG2000 and Gantrez ${ }^{\circledR}$ AN-mPEG2000 conjugates were prepared by a simple desolvation method with an ethanol:water mixture (1:1 by vol.) in the presence of calcium chloride. The incorporation of calcium enabled us to increase the yield of the preparative process (data not shown). This would be directly related with the presence of ionic interactions between the divalent metal 570 ion (calcium) and two neighbouring carboxylic groups in Gantrez ${ }^{\circledR}$ AN, which induces intrachain associations, promoting the cross-linking of the conjugate (Dong et al., 2011). The obtained poly(anhydride)-PEG2000 conjugate nanoparticles displayed a mean size higher than those in which mPEG2000 was used (around $420 \mathrm{~nm}$ vs. $340 \mathrm{~nm}$ ). Regarding the encapsulation of docetaxel, the amount of docetaxel loaded in this nanoparticles 575 was not dependent on the type of PEG employed for the conjugation and was calculated to be about $100 \mu \mathrm{g} / \mathrm{mg}$ nanoparticle, around 10-times the loading capacity of the unmodified poly(anhydride) (data not shown).

For the in vitro release of docetaxel from DTX-NP-PEG2 and DTX-NP-mPEG2 formulations, it is noteworthy that docetaxel was released at a considerably lower rate 580 under acidic conditions (SGF). This fact can be explained by the low propensity of the poly(anhydride) polymer to undergo hydrolysis in an acid medium (Cai et al., 2003) preventing the swelling and degradation of the nanoparticles. However, when nanoparticles were incubated under neutral conditions (SIF) a complete release of the loaded drug was reached with small differences between conjugate nanoparticles.

585 Concerning the pharmacokinetic study, a single dose of $30 \mathrm{mg}$ docetaxel per $\mathrm{kg}$ bw was selected. When free docetaxel was administered intravenously to mice, docetaxel disposition was nonlinear (Figure 4). This profile is characteristic of the anticancer drug, which has been widely described previously (Ogura et al., 2016; van Tellingen et al., 1999) and associated with the presence of Tween $^{\circledR} 80$ in the formula (Desai et al., 2008;

590 Gan et al., 2010). Likely, the pharmacokinetic values obtained were found to be in line with those previously reported (van Tellingen et al., 1999).

On the other hand, the oral administration of docetaxel after its encapsulation into the different poly(anhydride)-PEG conjugate nanoparticles offered high and prolonged in time drug plasma levels for at least 3 days (Figure 4). The long persistence of docetaxel

595 in plasma was confirmed by the increase of MRT and half-life $\left(\mathrm{t}_{1 / 2 z}\right)$ values as compared with the iv DTX (Table 3). Another important point to highlight would be that, for both types of nanoparticles, the plasma levels of docetaxel were always quantified within the therapeutic window of the anticancer drug (between $35 \mathrm{ng} / \mathrm{mL}$ and $2700 \mathrm{ng} / \mathrm{mL}$ ) (Saremi et al., 2011, Gan et al., 2010). Moreover, the high volume of distribution (V) observed for nanoencapsulated docetaxel formulations (Table 3), evidenced an 
effective arrival of the drug to the general circulation and an extensive distribution to tissues after absorption. Interestingly, the clearance of docetaxel when orally administered as nanoparticles was similar to that calculated for iv DTX. In this context, the relative oral bioavailability of nanoencapsulated docetaxel was calculated to be about $40 \%$ for DTX-NP-PEG2 and 56\% for DTX-NP-mPEG2. These values are significantly higher than the reported oral bioavailability of docetaxel (formulated as free drug), which would be lower than 4\% (Bardelmeijer et al., 2002; Hu et al., 2012).

These findings would be related with the mucus-permeating properties that may be obtained by the presence of PEG on the surface of nanoparticles. It is possible to 610 hypothesize that during the formation of nanoparticles the hydrophilic moieties of conjugates would be oriented outside towards aqueous medium forming a hydrophilic corona-type surface, which would confer a "slippery" effect in the resulting nanoparticles. As a consequence, the capability of nanoparticles to move and cross the protective mucus layer would be improved, facilitating their arrival to the surface of the enterocytes (Zabaleta et al., 2013). In this localization, the effect of the clearance mechanism (i.e., peristalsis) would be reduced, extending the residence time of nanoparticles in close contact with the epithelium surface in which the cargo would be release in a sustained way. It is important to highlight that these "slippery" properties are directly related with the surface graft density of PEG on nanocarriers (Wang et al., 620 2008), thus, high or dense PEG-packed surface greatly accelerated the transport of nanoparticles through the mucus, which would explain the higher oral bioavailability for DTX-NP-mPEG2 (high covalent grafting) compared with DTX-NP-PEG2. In parallel, the presence of PEG residues in this epithelial surface would facilitate its moderate inhibitory capacity of the intestinal efflux pump P-gp and cytochrome P450 (van Herwaarden et al., 2007; van Waterschoot et al., 2009), minimising the pre-systemic metabolism of docetaxel, and thus contributing to enhance its absorption.

Finally, to determine the function of poly(anhydride)-PEG conjugate nanoparticles for reducing the toxicity of docetaxel clinical formulation, DTX and DTX-NP-mPEG2 formulations were evaluated in healthy Balb/c mice. For the evaluation, three doses for 630 DTX (30 mg/ $/ \mathrm{kg} /$ injection), and nine doses for conjugate nanoparticles ( $20 \mathrm{mg} / \mathrm{kg} / \mathrm{dose}$ ) were administered to compare equitoxic doses. Thus, the accumulative dose for DTXNP-mPEG 2 was the same that for DTX $(90 \mathrm{mg} / \mathrm{kg})$ and close to the mean optimal total dose of Taxotere ${ }^{\circledR}$ in mice ( $~ 80 \mathrm{mg} / \mathrm{kg}$ ) (Bissery et al., 1991; Aston et al., 2017). The mice in the DTX group suffered marked weight loss of about $15 \%$ during the treatment period, 635 indicating severe toxicity, whereas the mice in the DTX-NP-mPEG2 suffered weight loss less than 5\% (Figure 5). Furthermore, the animals treated intravenously with DTX displayed important signs of disease stress after each administration and clinical sings of hypersensitivity and peripheral neurotoxicity following the treatment period (Table 4). These clinical manifestations would be directed related with the presence of the nonionic surfactant polysorbate 80 (Tween ${ }^{\circledR} 80$ ) as a solvent in Taxotere ${ }^{\circledR}$ formulation. The oxidation products and oleic acid present in $\operatorname{Tween}^{\circledR} 80$ may be the main cause of hypersensitivity reactions including serious dermatitis/necrosis (Ten Tije et al., 2003; Lucente et al., 2000). Moreover, Tween ${ }^{\circledR} 80$ is capable of producing vesicular degeneration, contributing to the multifactorial mechanism of taxane-induced peripheral neurotoxicity (Ten Tije et al., 2003). On the other hand, for free docetaxel, 
severe haematological adverse effects include anemia, leukopenia and neutropenia were observed in mice (Figures 6 and 7). On the contrary, for animals treated with nanoencapsulated docetaxel, the adverse effects were markedly less severe (Figures 6 and 7). The haematological adverse effects observed in animals treated with free docetaxel may be due to the myelosuppression effect, characterized by a pancytopenia in which the neutrophils are severely affected, observed when toxic levels of the anticancer drug are reached (Frederiks et al., 2015). In a similar way, the biochemical parameters (AST, ALT, urea and creatinine) reflected alterations in blood enzymes. Particularly, in the DTX group, a significant increase in ALT and AST activity was observed after the first iv administration, suggesting drug-associated hepatotoxicity (Li et al., 2010) (Table 5). By contrast, non-relevant changes were measured in animals treated with DTX-NP-mPEG2 (Table 5).

All of these results evidence the good tolerance for nanoencapsulated docetaxel orally administered, when compared with iv docetaxel. This observation may be directly related with the different profiles of the drug in plasma as well as to the absence of polysorbate 80 in the nanoparticle formulations. In fact, after iv docetaxel administration, polysorbate 80 adopts a micellar structure able to entrap docetaxel (Ten Tije et al.,2003). These micelles would act as the principal carriers of docetaxel in systemic circulation, decreasing the free drug fraction available for distribution to peripheral tissues (van Tellingen et al., 1999; Nassar et al., 2011). As a consequence, this accumulation of docetaxel in plasma would contribute to the common hematological side effects reported in clinical treatment (Cho et al., 2014; Gan et al., 2010).

\section{Conclusions}

670 This study demonstrated that poly(anhydride)-PEG conjugate nanoparticles were able to load docetaxel, presenting suitable characteristics for its oral administration. Pharmacokinetic studies revealed the high capability of these nanocarriers to enhance the oral bioavailability of docetaxel, particularly with nanoparticles made from mPEG2, offering plasma levels of the anticancer drugs within the therapeutic window for at least three days after administration. Furthermore, docetaxel-loaded nanoparticles orally administered displayed less severe signs of toxicity (i.e., hypersensitivity reactions, peripheral neurotoxicity, myelosuppression and hepatotoxicity) than free iv docetaxel, when equitoxic doses were compared.

Acknowledgements

This work was supported by grants from "Caja de Ahorros de Navarra" (CAN) project "Nanotecnología y medicamentos" (ref 10828) and by the Spanish Ministry of Science and Innovation (project SAF2008-02538). Luisa Ruiz-Gatón was also financially supported by a grant from "Asociación de Amigos Universidad de Navarra" (ADA).

\section{References}

Arbós, P., Campanero, M.A., Arangoa, M.A., Renedo, M.J., Irache, J.M., 2003. Influence of the surface characteristics of PVM/MA nanoparticles on their bioadhesive properties. J. Control. Release 89, 19-30. 
Aston, W.J., Hope, D.E., Nowak, A.K., Robinson, B.W., Lake, R.A., Lesterhuis, W.J., 2017. A systematic investigation of the maximum tolerated dose of cytotoxic chemotherapy with and without supportive care in mice. BMC Cancer 17, 684.

Bardelmeijer, H.A., Ouwehand, M., Buckle, T., Huisman, M.T., Schellens, J.H.S., Beijnen, J.H., van Tellingen, O., 2002. Low systemic exposure of oral docetaxel in mice resulting from extensive first-pass metabolism is boosted by ritonavir. Cancer Res. 62, 6158-6164.

Bissery, M.C., Guénard, D., Guéritte-Voegelein, F., Lavelle, F., 1991. Experimental antitumor activity of taxotere (RP 56976, NSC 628503), a taxol analogue. Cancer Res. 51, 4845-4852.

Cai, Q.X., Zhu, K.J., Chen, D., Gao, L.P., 2003. Synthesis, characterization and in vitro release of 5-aminosalicylic acid and 5-acetyl aminosalicylic acid of polyanhydrideP(CBFAS). Eur. J. Pharm. Biopharm. 255, 203-208.

Cho, H.J., Park, J.W., Yoon, I.S., Kim, D.D., 2014. Surface-modified solid lipid nanoparticles for oral delivery of docetaxel: enhanced intestinal absorption and lymphatic uptake. Int. J. Nanomed. 9, 495-504.

de Weger VA, Beijnen JH, Schellens JH. 2014. Cellular and clinical pharmacology of the taxanes docetaxel and paclitaxel--a review. Anticancer Drugs 25, 488-494.

Desai, N.P., Trieu, V., Hwang, L.Y., Wu, R., Soon-Shiong, P., Gradishar, W.G., 2008. Improved effectiveness of nanoparticle albumin-bound (nab) paclitaxel versus polysorbate-based docetaxel in multiple xenografts as a function of HER2 and SPARC status. Anticancer Drugs 19, 899-909.

Dong, X., Li, L., Xu, J., Guo, X., 2011. Rheological behavior of PMVE-MA aqueous solution with metallic cations. Front. Chem. Sci. Eng. 5, 126-130.

Dou, J., Zhang, H., Liu, X., Zhang, M., Zhai, G., 2014. Preparation and evaluation in vitro and in vivo of docetaxel loaded mixed micelles for oral administration. Colloids Surf. B Biointerfaces 114, 20-27.

Feng, S.S., Mei, L., Anitha, P., Gan, C.W., Zhou, W., 2009. Poly(lactide)-vitamin E derivate/montmorillonite nanoparticle formulations for the oral delivery of docetaxel. Biomaterials 30, 3297-3306.

Frederiks, C.N., Lam, S.W., Guchelaar, H.J., Boven, E., 2015. Genetic polymorphisms and paclitaxel- or docetaxel-induced toxicities: a systematic review. Cancer Treat. Rev. 41, 935-950.

Gan, C.W., Chien, S., Feng, S.S., 2010. Nanomedicine: enhancement of chemotherapeutical efficacy of docetaxel by using a biodegradable nanoparticle formulation. Curr. Pharm. Des. 16:2308-2320.

Haiqun, Z., Jinfeng, D., Yingjie, Z., Liu, A., Zhai, G., 2014. Advances in the formulations of non-injection administration of docetaxel. J. Drug Target. 22, 87-94.

Hekmat, A., Attar, H., Seyf Kordi, A.A., Iman, M., Jaafari, M.R., 2016. New oral formulation and in vitro evaluation of docetaxel-loaded nanomicelles. Molecules. 21, 1265.

Hennenfert, K.L., Govindan, R., 2006. Novel formulations of taxanes: a review. Old wine in a new bottle?. Ann. Oncol. 17, 735-749.

Hu, K., Cao, S., Hu, F., Feng, J., 2012. Enhanced oral bioavailability of docetaxel by lecithin nanoparticles: preparation, in vitro, and in vivo evaluation. Int. J. Nanomed. 7, 
3537-3545.

Hugger, E.D., Audus, K.L., Borchardt, R.T., 2002. Effects of poly(ethylene glycol) on efflux transporter activity in Caco-2 cell monolayers. J. Pharm. Sci. 91, 1980-1990.

Inchaurraga, L., Martín-Arbella, N., Zabaleta, V., Quincoces, G., Peñuelas, I., Irache, J.M., 2015. In vivo study of the mucus-permeating properties of PEG-coated nanoparticles following oral administration. Eur. J. Pharm. Biopharm. 97, 280-289.

Li, L., Tang, F., Liu, H., Liu, T., Hao, N., Chen, D., Teng, X., He, J., 2010. In vivo delivery of silica nanorattle encapsulated docetaxel for liver cancer therapy with low toxicity and high efficacy. ACS Nano. 4, 6874-6882.

Lucente, P., Lorizzo, M., Pazzaglia, M., 2000. Contact sensitivity to Tween 80 in a child. Contact Dermatitis 43, 172.

Malingré, M.M., Richel, D.J., Beijnen, J.H., Rosing, H., Koopman, F.J., Ten Bokkel Huinink, W.W., Schot, M.E., Schellens, J.H., 2001. Coadministration of cyclosporine strongly enhances the oral bioavailability of docetaxel. J. Clin. Oncol. 19, 1160-1166.

Mazzaferro, S., Bouchemal, K., Skanji, R., Gueutin, C., Chacun, H., Ponchel, G., 2012. Intestinal permeation enhancement of docetaxel encapsulated into methyl- $\beta$ cyclodextrin/poly(isobutylcyanoacrylate) nanoparticles coated with thiolated chitosan. J. Control. Release 162, 568-574.

Muggia, F., Kudlowitz, D., 2014. Novel Taxanes. Anticancer Drugs 25, 593-598.

Nassar, T., Attili-Qadri, S., Harush-Frenkel, O., Farber, S., Lecht, S., Lazarovici, P., Benita, S., 2011. High plasma levels and effective lymphatic uptake of docetaxel in an orally available nanotransporter formulation. Cancer Res. 71, 3018-3028.

Ogura, T., Tnaka, Y., Tamaki, H., Harada, M., 2016. Docetaxel induces Bcl-2- and proapoptotic caspase-independent death of human prostate cancer DU145 cells. Int. J. Oncol. 48, 2330-2338.

Ojer, P., de Cerain, A.L., Areses, P., Peñuelas, I., Irache, J.M., 2012. Toxicity studies of poly(anhydride) nanoparticles as carriers for oral drug delivery. Pharm. Res. 29, 2615-2627.

Olfert, E.D., Cross, B.M., McWilliam, A.A., 1993. Guide to the care and use of experimental animals. Vol. 1. Ottawa: Bradda Printing Savica; Canadian Council on Animal Care (CCAC).

Pandey, G., Mittapelly, N., Valicherla, G.R., Shukla, R.P., Sharma, S., Banala, V.T., Urandur, S., Jajoriya, A.K., Mitra, K., Mishra, D.P., Gayen, J.R., Mishra, P.R., 2017. P-gp modulatory acetyl-11-keto- $\beta$-boswellic acid based nanoemulsified carrier sys- tem for augmented oral chemotherapy of docetaxel. Colloids Surf. B Biointerfaces 155, 276-286.

Patel, K., Chowdhury, N., Doddapaneni, R., Boakye, C.H.A., Godugu, C., Singh, M. 2015. Piperlongumine for enhancing oral bioavailability and cytotoxicity of docetaxel in triple-negative breast cancer. J. Pharm. Sci. 104, 4417-4426.

775 Pellegrino, B., Boggiani, D., Tommasi, C., Palli, D., Musolino, A., 2017. Nab-paclitaxel after docetaxel hypersensitivity reaction: case report and literature review. Acta Biomed. 88, 329-333.

Saremi, S., Dinarvand, R., Kebriaeezadeh, A., Ostad, S.N., Atyabi, F., 2011. Enhanced oral delivery of docetaxel using thiolated chitosan nanoparticles: preparation, in vitro and in vivo studies. Int. J. Nanomed. 6, 119-128. 
Seo, Y.G., Kim, D.H., Ramasamy, T., Kim, J.H., Marasani, N., Oh, Y.K., Kim, D.W., Kim, J.K., Yong, C.S., Kim, J.O., Choi, H.G., 2013. Development of docetaxel-loaded solid selfnanoemulsifying drug delivery system (SNEDDS) for enhanced chemotherapeutic effect. Int. J. Pharm. 452, 412-420.

Song, C.K., Yoon, I.S., Kim, D.D., 2016. Poloxamer-based solid dispersions for oral delivery of docetaxel: Differential effects of F68 and P85 on oral docetaxel bioavailability. Int. J. Pharm. 507, 102-108.

Ten Tije, A.J., Verweij, J., Loos, W.J., Sparreboom, A., 2003. Pharmacological effects of formulation vehicles: implications for cancer chemotherapy. Clin. Pharmacokin. 42, 665-685.

van Herwaarden, A.E., Wagenaar, E., van der Kruijssen, C.M., van Waterschoot, R.A., Smit, J.W., Song, J.Y., van der Valk, M.A., van Tellingen, O., van der Hoorn, J.W., Rosing, H., Beijnen, J.H., Schinkel, A.H., 2007. Knockout of cytochrome P450 3A yields new mouse models for understanding xenobiotic metabolism. J. Clin. Invest. 117, 3583-3592.

van Tellingen, O., Beijnen, J.H., Verweij, J., Scherrenburg, E.J., Nooijen, W.J., Sparreboom, A., 1999. Rapid esterase-sensitive breakdown of polysorbate 80 and its impact on the plasma pharmacokinetics of docetaxel and metabolites in mice. Clin. Cancer Res. 5, 2918-2924.

van Waterschoot, R.A., Lagas, J.S., Wagenaar, E., van der Kruijssen, C.M., van Herwaarden, A.E., Song, J.Y., Rooswinkel, R.W., van Tellingen, O., Rosing, H., Beijnen, J.H., Schinkel, A.H., 2009. Absence of both cytochrome P450 3A and Pglycoprotein dramatically increases docetaxel oral bioavailability and risk of intestinal toxicity. Cancer Res. 69, 8996-9002.

Verweij, J., Calvel, M., Chevalier, B., 1994. Paclitaxel (Taxol) and docetaxel (Taxotere): not simply two of a kind. Ann. Oncol. 5, 495-505.

Vrignaud, V., Sémiond, D., Lejeune, P., Bouchard, H., Calvet, L., Combeau, C., Riou, J.F., Commerçon, A., Lavelle, F., Bissery, M.C., 2013. Preclinical antitumor activity of cabazitaxel, a semisynthetic taxane active in taxane-resistant tumors. Clin. Cancer Res. 19, 2973-2983.

Wang, Y.Y., Lai, S.K., Suk, JS, Pace, A., Coone, R., Hanes, J., 2008. Addressing the PEG mucoadhesivity paradox to engineer nanoparticles that "slip" through the human mucus barrier. Angew Chem. Int. Ed. Engl. 47, 9726-972.

Wolford, S.T., Schroer, R.A., Gohs, F.G., Gallo, P.P., Brodeck, M., Falk, H.B., Ruhren, R., 1986. Reference range data base for serum chemistry and hematology values in laboratory animals. J. Toxicol. Environ. Health 18, 161-188.

Wun, J., Shen, Q., Fang, L., 2013. Sulfobutylether- $\beta$-cyclodextrin/chitosan nanoparticles enhance the oral permeability and bioavailability of docetaxel. Drug Develop. Ind. Pharm. 39, 1010-1019.

820 Yoncheva, K., Gómez, S., Campanero, M.A., Gamazo, C., Irache, J.M., 2005a. Bioadhesive properties of pegylated nanoparticles. Expert Opin. Drug Deliv. 2005a;2:205-218.

Yoncheva, K., Lizarraga, E., Irache, J.M., 2005b. Pegylated nanoparticles based on poly(methyl vinyl ether-co-maleic anhydride): preparation and evaluation of their bioadhesive properties. Eur. J. Pharm. Sci. 24, 411-419.

Yin, Y.M., Cui, F.D., Mu, C.F., Choi, M.K., Kim, J.S., Chung, S.J., Shim, C.K., Kim, D.D., 2009. 
Docetaxel microemulsion for enhanced oral bioavailability: preparation and in vitro and in vivo evaluation. J. Control. Release 140, 86-94.

Zabaleta, V., Calleja, P., Espuelas, S., Corrales, L., Pío, R., Agüeros, M., Irache, J.M., 2013. Mucopenetrating nanoparticles: vehicles for the oral administration of paclitaxel. Ann. Pharm. Fr. 71, 109-118.

Zabaleta, V., Campanero, M.A., Irache, J.M., 2007. An HPLC with evaporative light scattering detection method for the quantification of PEGs and Gantrez in PEGylated nanoparticles. J. Pharm. Biomed. Anal. 44, 1072-1078.

Zhang, E., Xing, R., Liu., S, Li, P., 2019. Current advances in development of new docetaxel formulations. Expert Opin. Drug Deliv. 16, 301-312

Zhao, M., Su, M., Lin, X., Luo, Y., He, H., Cai, C., Tang, X., 2010. Evaluation of docetaxel intravenous lipid emulsion: pharmacokinetics, tissue distribution, antitumor activity, safety and toxicity. Pharm. Res. 27, 1687-1702. 


\section{Figure legends}

Figure 1. IR spectra of Gantrez ${ }^{\circledR}$ AN and its conjugates with either PEG2000 (PEG2) or mPEG2000 (mPEG2). Synthesis experimental conditions: PEG2000/poly(anhydride) ratio $0.05: 1$; $\mathrm{mPEG} 2000 /$ poly(anhydride) ratio 0.2:1; incubation time $3 \mathrm{~h}, 50$ 으.

Figure 2. Field emission scanning electron microscopy (FESEM) images of docetaxelloaded nanoparticles: A) DTX-NP-PEG2 and B) DTX-NP-mPEG2.

Figure 3. Docetaxel release profile from the PEG-conjugate nanoparticle formulations after incubation in simulated gastric fluid (SGF) and simulated intestinal fluid (SIF) at $37{ }^{\circ} \mathrm{C}$. Data represented as mean \pm S.D. $(n=3)$.

Figure 4. Docetaxel plasma concentration-time profile after the iv and oral administration of DTX (dose $30 \mathrm{mg} / \mathrm{kg} \mathrm{bw}$ ) and the oral administration of docetaxel loaded nanoparticles: DTX-NP-PEG2 and DTX-NP-mPEG2 (dose $30 \mathrm{mg} / \mathrm{kg}$ bw). Data are expressed as mean \pm S.D., $n=4$ per time point.

Figure 5. Evolution of the body weight (bw) of animals. Bw is expressed as a percentage of the starting weight of individual animals. Data represented as mean \pm S.D., $(n=4)$. ${ }^{*} p<0.05$ Mann-Whitney U-test iv DTX vs. control.

Figure 6. Hematological changes measured in mice through toxicity study compared with the basal levels. A) Red blood corpuscles count (RBC); B) Hematocrit (HCT); C) Hemoglobin (Hb); D) Mean corpuscular hemoglobin concentration (MCHC). Data represented as mean \pm S.D. $\left(^{*}\right)$ p $<0.05$ Mann Whitney U-test DTX day 0 (basal levels) vs. DTX day 14. $\left(^{* *}\right)$ p<0.01 Mann Whitney U-test DTX basal levels (day 0) vs. DTX day 14.

Figure 7. Hematological changes in white blood cells registered in mice through toxicity study. A) White blood corpuscles count (WBC); B) Absolut neutrophil counts (ANC). The dotted lines indicate the reported range of normal values (Wolford et al., 1986). Data represented as mean \pm S.D. ${ }^{* *} p<0.01$ Mann-Whitney U-test iv DTX vs. DTX-NP-mPEG2. 
Figure 1

COLOR

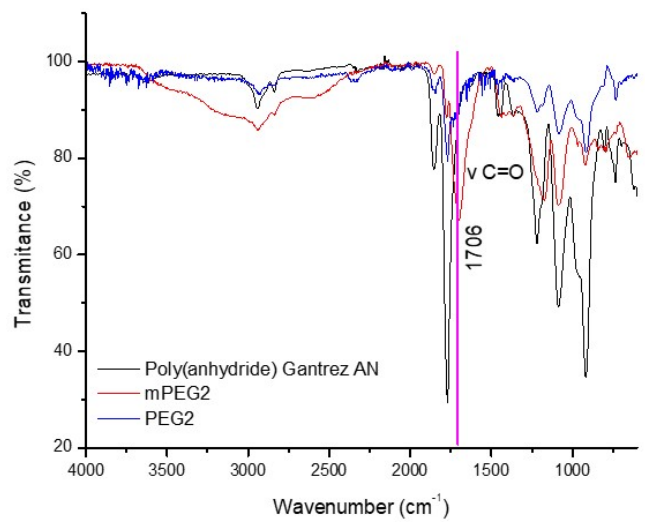


Figure 2

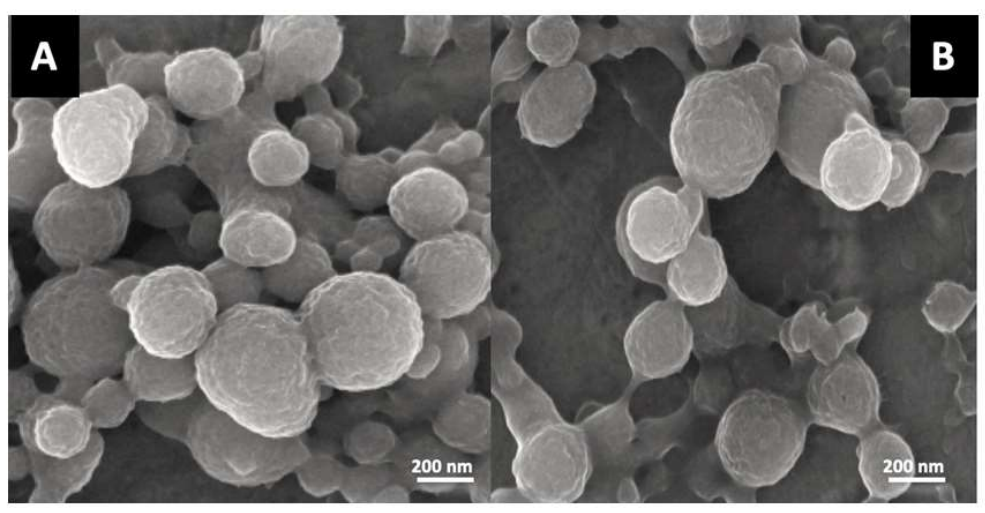




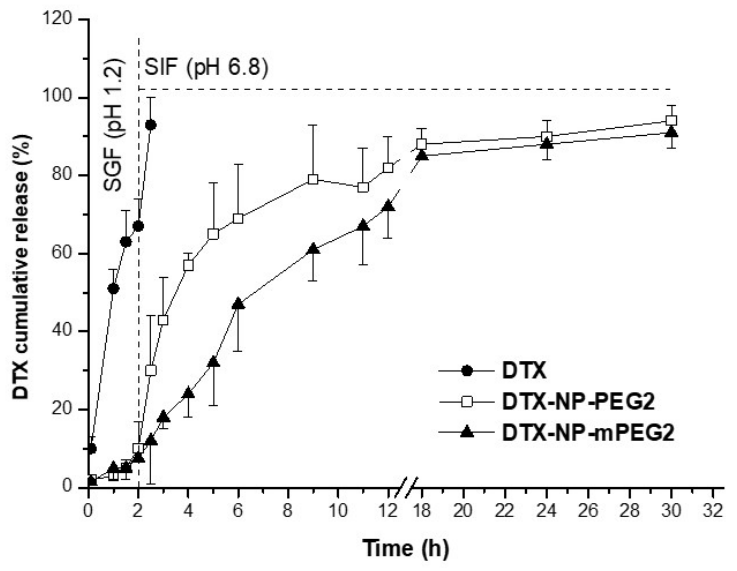


Figure 4

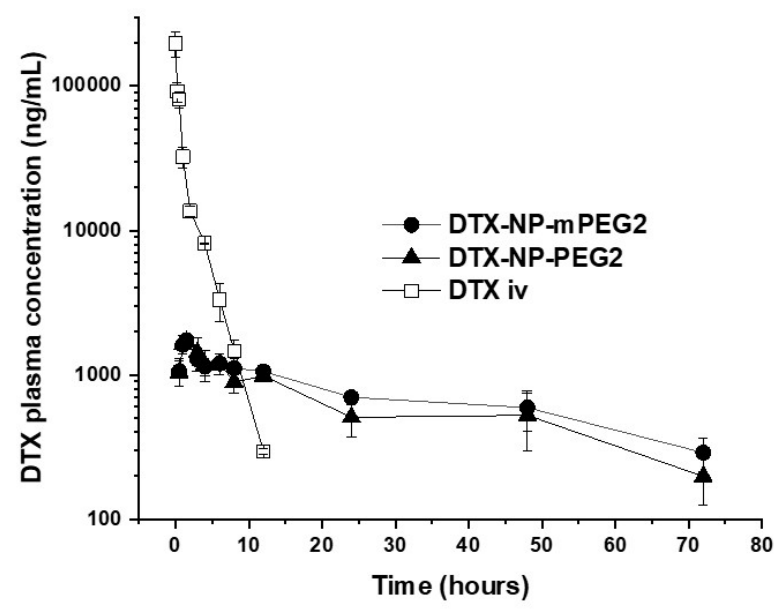




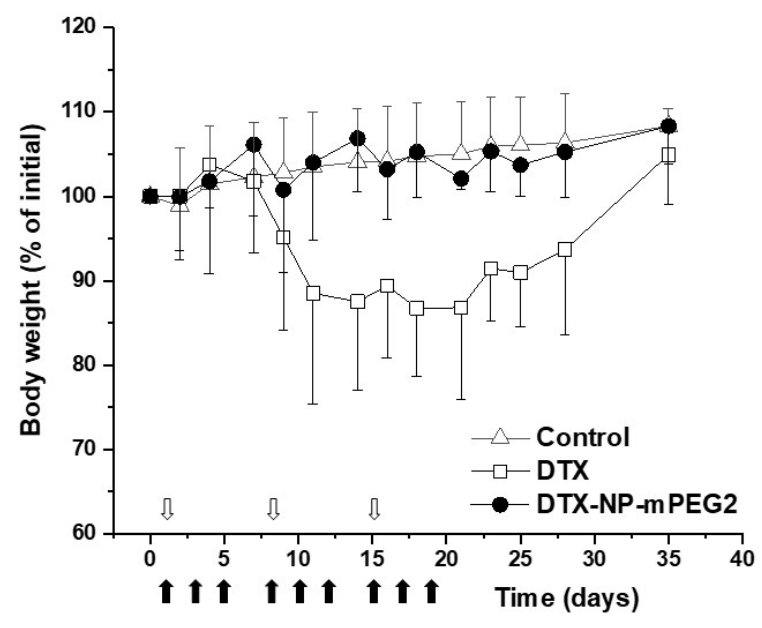



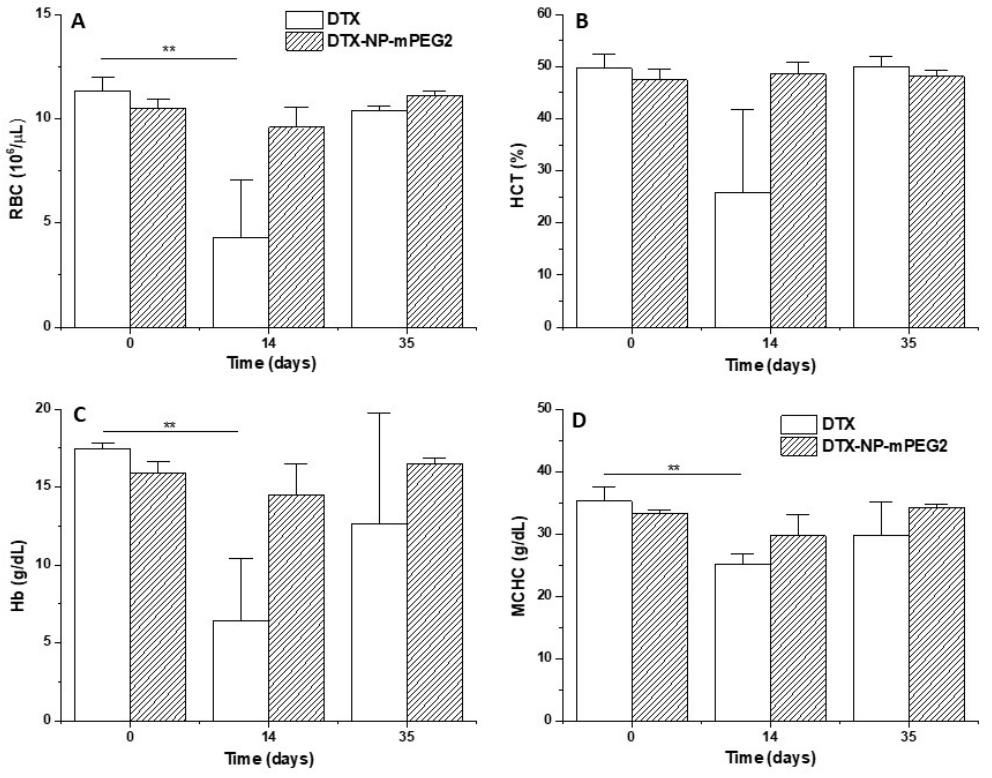

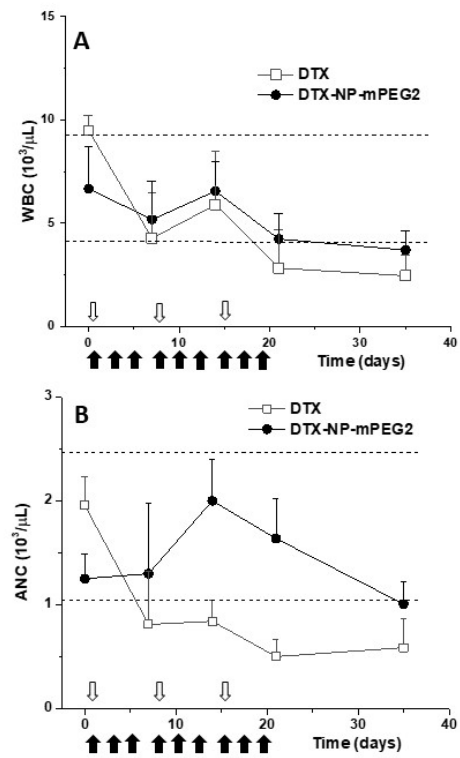
Table 1. Estimated degree of substitution (\% DS) and amount of PEG attached for the different conjugates synthesised calculated by HPLC-ELSD. PA: poly(anhydride). Data are expressed as mean \pm S.D. $(n=4)$.

\begin{tabular}{c|c|c|c}
\hline & PEG-to-PA ratio & DS (\%) & $\begin{array}{c}\text { PEG attached } \\
\text { ( } \mu \mathrm{g} / \mathrm{mg} \text { conjugate) }\end{array}$ \\
\hline PEG2 & $0.05: 1$ & $2.2 \pm 0.5^{*}$ & $22.1 \pm 3.2^{*}$ \\
\hline mPEG2 & $0.2: 1$ & $8.1 \pm 0.9$ & $80.5 \pm 9.1$ \\
\hline
\end{tabular}

* $p<0.05$ Mann Whitney U-test DTX-NP-PEG2 vs. DTX-NP-mPEG2. 
Table 2. Physico-chemical characterization of nanoparticles based on the synthetised conjugates. Data are expressed as mean \pm S.D. $(n=4)$. NP-PEG2: control nanoparticles obtained from the Gantrez ${ }^{\circledR}$ AN-PEG2000 conjugate; NP-mPEG2: control nanoparticles obtained from the Gantrez ${ }^{\circledR}$ AN-mPEG2000 conjugate; DTX-NP-PEG2: docetaxel-loaded in nanoparticles obtained from the Gantrez ${ }^{\circledR}$ AN-PEG2000 conjugate; DTX-NP-mPEG2: docetaxel-loaded in nanoparticles obtained from the Gantrez ${ }^{\circledR}$ AN-mPEG2000 conjugate.

\begin{tabular}{l|c|c|c|c|c}
\hline \multicolumn{1}{|c|}{ Formulation } & Size $(\mathbf{n m})$ & $\begin{array}{c}\text { Zeta } \\
\text { Potential } \\
(\mathbf{m V})\end{array}$ & $\begin{array}{c}\text { Yield } \\
\mathbf{( \% )}\end{array}$ & $\begin{array}{c}\text { EE } \\
\mathbf{( \% )}\end{array}$ & $\begin{array}{c}\text { DTX } \\
\text { loading } \\
(\mu \mathrm{g} / \mathrm{mg} \mathrm{NP})\end{array}$ \\
\hline NP-PEG2 & $307 \pm 9$ & $-36 \pm 2$ & $70 \pm 1$ & - & - \\
\hline DTX-NP-PEG2 & $415 \pm 4$ & $-33 \pm 2$ & $64 \pm 9$ & $58 \pm 7$ & $94 \pm 5$ \\
\hline NP-mPEG2 & $297 \pm 9$ & $-40 \pm 2$ & $68 \pm 2$ & - & - \\
\hline DTX-NPmPEG2 & $339 \pm 7$ & $-37 \pm 5$ & $60 \pm 9$ & $61 \pm 9$ & $100 \pm 6$ \\
\hline
\end{tabular}


Table 3. Pharmacokinetic parameters of docetaxel obtained after the iv and oral administration of the commercial docetaxel (DTX) and nanoparticles encapsulating docetaxel at a single dose of $30 \mathrm{mg} / \mathrm{kg}$ bw to female Balb/c mice.

\begin{tabular}{c|c|c|c|c|c|c|c|c|c|c}
\hline Formulation & Route & $\begin{array}{c}\text { AUC } \\
(\mu \mathrm{g} \mathrm{h} / \mathbf{m L})\end{array}$ & $\begin{array}{c}\mathbf{C}_{\max } \\
(\boldsymbol{\mu g} / \mathbf{m L})\end{array}$ & $\begin{array}{c}\mathbf{T}_{\max } \\
(\mathbf{h})\end{array}$ & $\begin{array}{c}\mathbf{M R T} \\
(\mathbf{h})\end{array}$ & $\begin{array}{c}\mathbf{T}_{1 / 2 \mathbf{z}} \\
(\mathbf{h})\end{array}$ & $\begin{array}{c}\mathrm{K}_{\mathrm{e}} \\
(\mathrm{h})\end{array}$ & $\begin{array}{c}\mathbf{C l} \\
(\mathbf{L} / \mathbf{h} / \mathbf{k g})\end{array}$ & $\begin{array}{c}\mathbf{V} \\
(\mathbf{L} / \mathbf{k g})\end{array}$ & $\begin{array}{c}\mathbf{F r} \\
(\mathbf{\%})\end{array}$ \\
\hline DTX & iv & $145.4 \pm 4.9$ & $177.9 \pm 25.1$ & - & $1.4 \pm 0.1$ & $1.5 \pm 0.1$ & $0.46 \pm 0.01$ & $0.2 \pm 0.1$ & $0.5 \pm 0.1$ & 100 \\
\hline DTX & p.o & N.D & N.D & N.D & N.D & N.D & N.D & N.D & N.D & N.D \\
\hline DTX-NP-PEG2 & p.o & $58.1 \pm 7.8^{*} \dagger$ & $1.7 \pm 0.2$ & 2 & $58.7 \pm 7.8^{*}$ & $35.8 \pm 9.2^{*}$ & $0.03 \pm 0.02^{*}$ & $0.2 \pm 0.1$ & $11.2 \pm 4.1^{*}$ & 40.1 \\
\hline DTX-NP-mPEG2 & p.o & $80.6 \pm 9.8^{*}$ & $1.7 \pm 0.1$ & 1.5 & $61.1 \pm 7.6^{*}$ & $43.1 \pm 4.3^{*}$ & $0.02 \pm 0.01^{*}$ & $0.2 \pm 0.1$ & $14.1 \pm 2.3^{*}$ & 55.5 \\
\hline
\end{tabular}

AUC: Area under the concentration-time curve from time 0 to $t h ; C_{\max }$ : Peak plasma concentration; $T_{\max }$ : Time to reach peak plasma concentration; $\mathrm{t}_{1 / 2}$ : Half-life of the terminal phase; Ke: elimination rate constant; $\mathrm{Cl}$ : Clearance; $\mathrm{V}$ : Volume of distribution; MRT: Mean residence time; Fr: relative oral bioavailability. $\left(^{*}\right)$ p $<0.05$ Mann-Whitney U-test DTX-NP-PEG2 vs. DTX iv, DTX-NP-mPEG2 vs. DTX iv.; (†) p<0.05 Mann Whitney U-test DTX-NP-PEG2 vs. DTX-NP-mPEG2. 
Table 4. Mortality rate and signs scored after iv administration of docetaxel (dose 30 $\mathrm{mg} / \mathrm{kg}$ bw; weekly) and oral administration of DTX-NP-mPEG2 (dose $20 \mathrm{mg} / \mathrm{kg}$ bw; three times per week) during three consecutive weeks (Control and DTX, n=5; DTX-NP-mPEG2, $n=8)$.

5

\begin{tabular}{l|c|c|c|c|c|c}
\hline Treatment & Piloerection & Passivity & $\begin{array}{c}\text { Skin } \\
\text { reactions }\end{array}$ & $\begin{array}{c}\text { GI } \\
\text { toxicity }\end{array}$ & $\begin{array}{c}\text { Peripheral } \\
\text { neuropathy }\end{array}$ & Mortality \\
\hline Control & - & - & - & - & - & $0 / 5$ \\
\hline DTX & +++ & ++ & +++ & - & +++ & $1 / 5$ \\
\hline $\begin{array}{l}\text { DTX-NP- } \\
\text { mPEG2 }\end{array}$ & - & - & - & - & - & $1 / 8$ \\
\hline
\end{tabular}

Severity of the signs: $(-)$ no signs; $(+)$ weak; $(++)$ moderate; $(+++)$ strong. Gl: Gastrointestinal 
Table 5. Biochemical parameters detected on day 0 (basal levels) and on day 7 and 35 after the first dose of iv DTX or oral docetaxel-loaded in nanoparticles obtained from the Gantrez $^{\circledast}$ AN-mPEG2000 conjugate. AST: Aspartate transaminase; ALT: Alanine transaminase.

5

\begin{tabular}{l|c|c|c|c|c|c}
\hline & \multicolumn{2}{|c|}{ Day 0 } & \multicolumn{2}{c|}{ Day 7 } & \multicolumn{2}{c}{ Day 35 } \\
\hline & DTX & $\begin{array}{l}\text { DTX-NP- } \\
\text { mPEG2 }\end{array}$ & DTX & $\begin{array}{l}\text { DTX-NP- } \\
\text { mPEG2 }\end{array}$ & DTX & $\begin{array}{c}\text { DTX-NP- } \\
\text { mPEG2 }\end{array}$ \\
\hline AST (U/L) & $94.5 \pm 23.4$ & $96.3 \pm 26.4$ & $154.5 \pm 55.6^{*}$ & $71.7 \pm 5.1$ & $94.8 \pm 24.9$ & $75.3 \pm 23.7$ \\
\hline ALT (U/L) & $46.1 \pm 11.1$ & $36.1 \pm 2.8$ & $62.5 \pm 2.6^{*}$ & $33.7 \pm 4.7$ & $45.5 \pm 11.5$ & $43.8 \pm 22.1$ \\
\hline $\begin{array}{l}\text { Urea } \\
\text { (mg/dL) }\end{array}$ & $39.3 \pm 2.6$ & $34.1 \pm 5.3$ & $33.1 \pm 8.5$ & $40.3 \pm 7.5$ & $31.8 \pm 8.9$ & $36.7 \pm 10.6$ \\
\hline $\begin{array}{l}\text { Creatinine } \\
\text { (mg/dL) }\end{array}$ & $0.1 \pm 0$ & $0.1 \pm 0$ & $0.1 \pm 0$ & $0.1 \pm 0$ & $0.2 \pm 0.1$ & $0.1 \pm 0$ \\
\hline
\end{tabular}

${ }^{*} p<0.05$ Mann-Whitney U-test iv DTX vs. DTX-NP-mPEG2 